\title{
Clinico-epidemiological study of childhood stroke in Children Welfare Teaching Hospital/Baghdad
}

\author{
Husham Z.Hammoodi* \\ Lamyaa A.Hammoodi** \\ Akram M. Al-Mahdawi***
}

\author{
FIBPN, FICMS (ped.), MBCHB \\ CABP, MBCHB \\ CABM, MRCP, FRCP
}

\begin{abstract}
:
Background: The annual incidence of stroke in children after the newborn period is approximately 2.3 per 100000. Half are ischemic, and half are non-traumaticintracerebral and subarchnoidal hemorrhages.

Objectives: To study the etiologic factors, clinical presentation andoutcome of stroke among children admitted to children welfare teaching hospital/Baghdad.

Patient and methods: A prospective study was carried out in Children Welfare Teaching Hospital;Children age ranged between 1 month -13 years and was admitted to pediatric neurology ward between 1 st of November 2013 and 1st of November 2014. After carful clinical history, physical and neurological examinations, the diagnosis of brain stroke was confirmed in all patients by computerized tomography (CT) and/or magnetic resonance imaging (MRI). Patients included in this study were those diagnosed as having ischemic stroke, hemorrhagic stroke.

Results: The total number of cases were 61,36 were male (59\%). The age at onset ranged from 1-156 months. Ischemic stroke constituted 39 patients (63.9\%). The most common etiologic factors for the ischemic stroke were protein $\mathrm{C}$ deficiency $(9,23.1 \%)$. The most common etiologic factor for hemorrhage was bleeding disorders in about $50 \%$ of patients. The most common presenting features were hemiplegia, seizure, alteration of consciousness; Cranial nerves palsy is mostly present in the ischemic stroke $(14,35.9 \%)$ and only in one patient $(4.5 \%)$ of hemorrhagic stroke.

Conclusions: Ischemic stroke is more common than hemorrhagic stroke in pediatric age group. The significant risk factors for ischemic stroke are protein $\mathrm{C}$ deficiency, Congenital heart disease(CHD) and positive family history, while vitamin K deficiency, prolong Partial thromboplastin time (PTT) and trauma are significant for hemorrhagic stroke. The most common clinical features of both types of stroke are hemiparesis, siezure and alteration of consciousness.

Keywords:Ischemic stroke, Hemorrhagic stroke, Children Welfare Teaching Hospital.
\end{abstract}

\section{Introduction:}

The annual incidence of stroke in children after the newborn period is approximately 2.3 per 100000 . Half are ischemic, and half are non traumatic intracerebral and subarchnoidal hemorrhages.(1) In view of its different clinical manifestations, its diverse causes and low suspicion for stroke in pediatrics, these data may underestimate the true incidence of stroke in this group. Stroke recurrence in children can reach $20 \%$, and in the presence of multiple risk factors recurrence can be as high as $42 \%$.(2) One of the first epidemiological finding from the international pediatric stroke study found a male predominance in childhood Arterial Ischemic Stroke (AIS) in all age group studied.(3) The Peak age for both ischemic stroke and intraparanchymal brain hemorrhage is the first year of life. (4) The lifelong morbidity of stroke in a child last decades,

*Dept. of Pediatric neurologist|Children Welfare Teaching Hospital, Baghdad, Iraq.

Email:Heshamdr1012@yahoo.com

**Assistant Professor of pediatrics Chairman of scientific council of pediatric.

***Chairman of scientific council of Neurology Medicine. amplifying its impact on society and the quality of life of a child and their family.(5)

Despite the small quantity of published data, the problem is of growing significance in the pediatric population since pediatric ischemic stroke can nowadays be detected much more efficiently than in the past.(6) The majority of AIS have underlying diseases such as sickle cell disease and congenital and acquired cardiac disease, whereas causes of hemorrhagic stroke include vascular malformations and trauma.(7) Almost half of children with AIS are known to have a stroke risk factor at time of infarction, and more than one vascular risk factors can be identified in at least two thirds of children after a thorough evaluation.(8) Even after extensive investigation, no cause can be discovered in up to $30 \%$ of children with AIS.(9) Hemiplegia is the most common presentation of AIS in childhood, and the middle cerebral artery territory is the most common location of infarcts in children. Other common presenting features include altered mental status and focal signs such as aphasia and visual disturbance. Stroke in posterior circulation can present as ataxia, vertigo, or vomiting and is 
often mistaken by families and physicians for viral infection. (10) Noncontrast CT is sensitive for acute bleeding and should be obtained urgently to exclude a hemorrhagic cause of stroke. (11) MRI and Magnetic resonance arteriography (MRA) of the intracranial (and ideally neck) arteries is indicated for any child with suspected acute AIS(12). The aim is to study the risk factors, the clinical spectrum, and outcomes of pediatric stroke among children admitted to Children welfare teaching hospital/Baghdad.

\section{Patient and methods:}

A prospective study was carried out in Children Welfare Teaching Hospital / Medical City Complex/ Baghdad, children aged 1 month -13 years were included. They were admitted to pediatric neurologicunit between the 1st of November 2013 and 1st of November 2014.After carful clinical history, physical and neurological examinations, the diagnosis of brain stroke was confirmed in all patients in X-Ray institute/Medical city complex by computerized tomography andlor magnetic resonance imaging. Baseline investigations performed at the time of presentation including complete blood counts (CBC) and blood film, blood sedimentation rate and/or C-reactive protein, blood glucose, liver-function tests, blood urea, creatinine, electrolytes, total cholesterol, triglycerides, ProthrombinTime and PTT. Some patients were sent for protein $\mathrm{C}$ and $\mathrm{S}$, antithrombin, plasma and CSF lactate, and screen for metabolic disorders (mitochondrial, and aminoacidopathies) depending on case presentation.

Cases were classified into ischemic and Hemorrhagic stroke as follow:

1-Ischemic stroke; defined as acute neurologic deficits lasting more than 24 hours, with neuroimaging showing parenchymal infarction.

2- Hemorrhagic stroke; defined as an acute neurologic deficit with neuroimaging showing intracranial hemorrhage which include subarachnoid hemorrhage and intracerebral hemorrhage.

Patients included in this study were those diagnosed as had ischemic stroke, Hemorrhagic stroke, cerebral venous thrombosis confirmed by neuroimaging (CT, MRI) study. Exclusion criteria include:

1-Cases with hemiplagia but normal neuroimaging study.

2-All patients without typical radiological finding were excluded.

After discharge, the patients were followed in the neurologic clinic for one year to determine the improvement or sequel.

Data were translated into a computerized database structure. The database was examined for errors using range and logical data cleaning methods, and inconsistencies were remedied. An expert statistical advice was sought for. Statistical analyses were done using IBMSPSS version 21 computer software (Statistical Package for Social Sciences) in association with Microsoft Excel 2013. P value $<0.05$ considered to be significant.

Results:

The total number of cases were 61,36 were male $(59 \%)$ and 25 female $(41 \%)$. The male to female ratio was $1.8: 1$ in ischemic stroke and 1:1 in Hemorrhagic stroke. Patients with stroke were classified into; ischemic stroke (39 patients (63.9\%) and Hemorrhagic stroke (22 patients (36.1\%). The ratio of ischemic stroke to Hemorrhagic stroke was 1.8:1. The most common affected age group was between 1 and 5 years $(46.2 \%)$ in ischemic stroke and in first year in Hemorrhagic stroke $(50 \%)$. The age at onset ranged from 1-156 months, with a mean of 37.8 months for ischemic stroke and 30.7 months for Hemorrhagic stroke. The patients with Hemorrhagic stroke were younger than those with ischemic stroke, and the association was statistically not significant $(\mathrm{P}$ value $=0.47)$. (Table 1)The etiologic factors for the ischemic stroke were protein C deficiency $(9,23.1 \%)$, followed by CHD (8, 20.5\%) and CNS infection $(7,17.9 \%)$. The most common risk factor for Hemorrhagic stroke was bleeding disorders (vit.K deficiency $(9,40.9 \%)$, platelets deficiency $(2,9.1 \%)$, while 4 patients $(18.2 \%)$ were trauma (Table 2$)$.Eleven cases were classified as cryptic stroke with no etiological factors could be identified, 10 of them had ischemia and one hemorrhagic stroke.Eleven cases had a multiple risk factors $(18 \%), 6$ of them present with bilateral stroke. The most common presentation among patient with ischemic stroke was hemiplegia $(84.6 \%)$, but in Hemorrhagic stroke the alteration of consciousness was the most common $(86.4 \%$ ), with $p$ value $<0.05$ (table 3 ). In both types of stroke the second common presentation was seizure (61.5\% in ischemic and 68.2\% in Hemorrhagic stroke).Most of the stroke occur in the left side (27 cases), in 20 cases, lesion occur in the right side of the brain, those occur in the right side were mainly hemorrhagic due to trauma or venous infarction. The large numbers of patients had only one lesion, 14 cases had bilateral lesions on MRI or CT scan, most of them presented with a multiple etiologic factors.Parietal lobe was most commonly affected in both ischemic and Hemorrhagic stroke $(66.7 \%, 72.7 \%$, respectively). The second for both types was frontal (46.2\% for ischemic, $36.4 \%$ for Hemorrhagic stroke). Occipital lobe was mostly affected by hemorrhage $(31.8 \%)$, and the association was statistically highly significant $(\mathrm{OR}=5.6, \mathrm{P}=0.027)$. (Table4) Regarding the duration of hospitalization which is ranged from 3-30 days, with a mean of 11.4 days for ischemic stroke and 12.3 days for hemorrhagic type.Mortality rate was $9.1 \%$ for hemorrhagic stroke and $2.6 \%$ for ischemic stroke. Three out of 61 cases died; two of them due to hemorrhagic stroke (bleeding disorders) and one had both venous and arterial ischemia as a result of protein $\mathrm{C}$ deficiency. Recovery was judged complete in 11 (18\%) of patients, and neurological sequel in 47 (77\%). (Table 5) 
Table 1: General description of the study samples

\begin{tabular}{|c|c|c|c|c|c|c|c|c|}
\hline & \multicolumn{8}{|c|}{ Type of stroke } \\
\hline & \multicolumn{2}{|c|}{ Ischemic } & \multicolumn{2}{|c|}{ Hemorrhagic } & \multirow[b]{2}{*}{ OR } & \multirow[b]{2}{*}{$95 \mathrm{C} \%$} & \multirow[b]{2}{*}{$\mathbf{P}$} & \multirow[b]{2}{*}{ Total } \\
\hline Gender & $\mathbf{N}$ & $\%$ & $\mathbf{N}$ & $\%$ & & & & \\
\hline Male & 25 & 64.1 & 11 & $\mathbf{5 0}$ & - & - & - & 36 \\
\hline Female & 14 & 35.9 & 11 & 50 & - & - & - & 25 \\
\hline \multicolumn{9}{|l|}{ Age group (Y) } \\
\hline $1>Y$ & 12 & 30.7 & 11 & 50 & - & - & - & 23 \\
\hline $15-Y$ & 18 & 46.2 & 6 & 27.3 & - & - & - & 24 \\
\hline $5+$ & 9 & 23.1 & 5 & 22.7 & - & - & - & 14 \\
\hline Positive family history of stroke & 4 & 10.3 & 2 & 9.1 & 0.9 & $(0.15-5.21)$ & $0.88[\mathrm{NS}]$ & 6 \\
\hline Positive history of similar stroke & 8 & 20.5 & $\mathbf{0}$ & 0.0 & - & - & $<0.001$ & 8 \\
\hline
\end{tabular}

Table 2: The patient's distribution according to their type of stroke and etiologic factors

\begin{tabular}{|c|c|c|c|c|c|c|c|}
\hline & \multicolumn{2}{|c|}{ Ischemic } & \multicolumn{2}{|c|}{ Hemorrhagic } & OR & $95 \%$ CI & \\
\hline Etiologic factors * & $\mathbf{N}$ & $\%$ & $\mathbf{N}$ & $\%$ & & & \\
\hline Trauma & $\mathbf{0}$ & $\mathbf{0 . 0}$ & 4 & 18.2 & & & 0.014 \\
\hline platelets deficiency & 3 & 7.7 & 2 & 9.1 & 1.2 & $(0.18-7.79)$ & 1[NS] \\
\hline protein c abnormality & 9 & 23.1 & $\mathbf{0}$ & 0.0 & & & 0.02 \\
\hline MoyaMoya & 2 & 5.1 & 1 & 4.5 & $\mathbf{0 . 8 8}$ & $(0.08-10.31)$ & 1[NS] \\
\hline Vit K deficiency & $\mathbf{0}$ & $\mathbf{0}$ & 9 & 40.9 & & & $<0.001$ \\
\hline Arterio-Venous Malformation & $\mathbf{0}$ & 0.0 & 2 & 9.1 & & & $0.13[\mathrm{NS}]$ \\
\hline metabolic disorder & 2 & 5.1 & 1 & 4.5 & 0.88 & $(0.08-10.31)$ & $1[\mathrm{NS}]$ \\
\hline CHD (congenital heart disease) & 8 & 20.5 & $\mathbf{0}$ & 0.0 & & & 0.042 \\
\hline Hyperlipidemia & $\mathbf{1}$ & 2.6 & $\mathbf{1}$ & 4.3 & 0.6 & $\overline{(0.04-10)}$ & 1[NS] \\
\hline renal disease & $\mathbf{0}$ & 0.0 & 2 & 9.1 & & & $0.13[\mathrm{NS}]$ \\
\hline$\overline{\mathbf{D M}}$ & $\mathbf{1}$ & 2.6 & $\mathbf{0}$ & $\mathbf{0 . 0}$ & & & $1[\mathrm{NS}]$ \\
\hline CNS infection & 7 & $\mathbf{1 7 . 9}$ & $\mathbf{1}$ & 4.5 & 0.22 & $(0.02-1.9)$ & $0.24[\mathrm{NS}]$ \\
\hline
\end{tabular}

*some patients have a more than one risk factors.

*Eleven patients classified as cryptic stroke.

Table 3: Distribution of the study group by type of stroke and presenting features

\begin{tabular}{|c|c|c|c|c|c|c|c|}
\hline \multirow[b]{2}{*}{ Presenting features } & \multicolumn{2}{|c|}{ Ischemic $(n=39)$} & \multicolumn{2}{|c|}{ Hemorrhagic $(n=22)$} & \multirow[t]{2}{*}{ OR } & \multirow[t]{2}{*}{$95 \%$ CI } & \multirow[t]{2}{*}{$\mathbf{P}$} \\
\hline & $\mathbf{N}$ & $\%$ & $\mathbf{N}$ & $\%$ & & & \\
\hline Hemiplegia & 33 & 84.6 & 14 & 63.6 & 0.32 & $(0.09$ - 1.09) & $0.06[\mathrm{NS}]$ \\
\hline Seizure & 24 & 61.5 & 15 & 68.2 & 1.34 & $(0.44-4.04)$ & $0.6[\mathrm{NS}]$ \\
\hline Vomiting & 2 & 5.1 & $\mathbf{0}$ & 0.0 & & & $0.53[\mathrm{NS}]$ \\
\hline Fever & 17 & 43.6 & 10 & 45.5 & 1.08 & $(0.38$ - 3.09) & 0.89 [NS] \\
\hline speech problem & 9 & 23.1 & 10 & 45.5 & 2.78 & $(0.9-8.53)$ & $0.07[\mathrm{NS}]$ \\
\hline cranial nerve palsy & 14 & 35.9 & 1 & 4.5 & 0.09 & $(0.01-0.7)$ & 0.006 \\
\hline Headache & 9 & 23.1 & 3 & 13.6 & 0.53 & $(0.13$ - 2.19) & $0.51[\mathrm{NS}]$ \\
\hline disturbed level of consciousness & 18 & 46.2 & 19 & 86.4 & 7.39 & $(1.88-29.1)$ & 0.002 \\
\hline
\end{tabular}

Table 4: Localization of lesion in diagnostic imaging

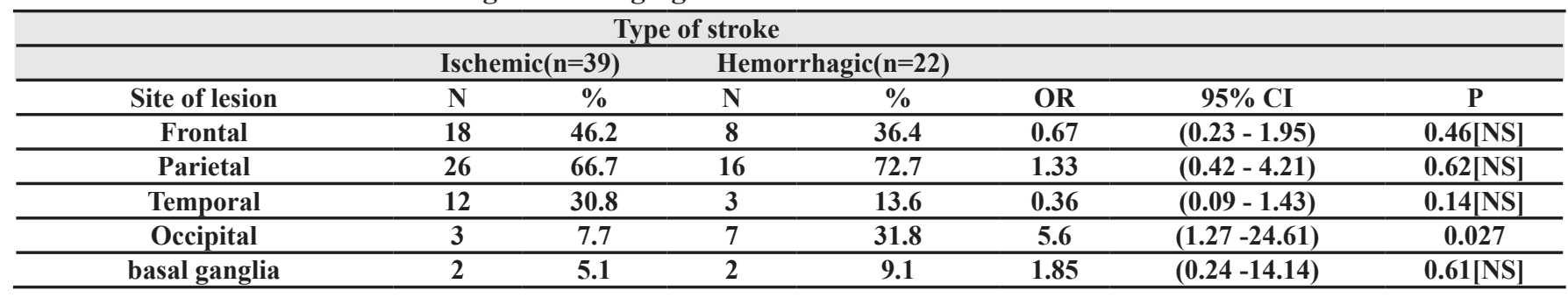

Table 5: outcome at discharge in children with stroke

\begin{tabular}{|c|c|c|c|c|c|c|c|}
\hline & \multicolumn{2}{|c|}{ Ischemic } & \multicolumn{2}{|c|}{ Hemorrhagic } & \multirow[b]{2}{*}{ OR } & \multirow[b]{2}{*}{$95 \%$ CI } & \multirow[b]{2}{*}{$\mathbf{P}$} \\
\hline Outcome & $\mathbf{N}$ & $\%$ & $\mathbf{N}$ & $\%$ & & & \\
\hline No sequelae & 6 & 15.4 & 5 & 22.7 & & & \\
\hline Neurological sequelae & 32 & 82.1 & 15 & 68.2 & 0.6 & $(0.15-2.14)$ & $0.4[\mathrm{NS}]$ \\
\hline Death & 1 & 2.6 & 2 & 9.1 & 2.4 & $(0.16-34.93)$ & $0.52[\mathrm{NS}]$ \\
\hline Total & 39 & 100.0 & 22 & 100.0 & & & \\
\hline
\end{tabular}




\section{Discussion:}

This study found that ischemic stroke more common than hemorrhagic stroke, this result agreed with other studies done in France, (13) Southeast Asia,(14) and Saudi Arabia, (15) in which ischemic stroke were higher than Hemorrhagic stroke in children.Regarding the gender, our results were similar to those found in Saudi Arabian study; (16) but in Californian study (4) relying administrative data found that boys had a higher incidence of childhood stroke than girls for both ischemic and hemorrhagic types with a relative risk of 1.25 for ischemic stroke.The mean age at first diagnosis was found to be 37.8 months for ischemic stroke and 30.7 months for Hemorrhagic stroke. Salih et al (17) demonstrate a similar age trend, but other studies like this done in Melbourne (18) showed an older age than the current study, this could be due to including children with age up to 18 years rather than 13years, and larger number of sample. More than $50 \%$ of patients with stroke have consanguineous parents. All cases present with recurrent stroke are ischemic, most of them had positive family history of stroke in children, and also most patients with prothrombotic risk factors (e.g. protein C, lipoprotein abnormality) showed the highest rate of restroke, this result agreed with study done in Germany (Sträter R. et al in 2002).(19)

The most common etiology of ischemic stroke is deficiency of proteins of coagulation, Bonduel et al (20) verified that $30 \%$ of arterial ischemic stroke(AIS) patients presented prothrombotic disorders, this occurred in about $23 \%$ of patients in our study, this may due to great number of associated infections, because the acquired deficiencies of the proteins of coagulation and thrombosis of central nervous system are associated with infections,(21) and it could be a consequence of the inclusion of the early age children in our research, because the prevalence of prothrombotic risk factors is high in this age group.(22)The reasons for a high percent of ischemic stroke in cardiac disease were the hyperviscosity in congenital cyanotic heart diseases and emboli in other heart diseases. Mustafa et al (23) found (5.8\%) of all stroke patients were due to CHD.The present research found that $13.1 \%$ of patients with strokewere due to acute infection. Probably an inflammatory process of the intracranial vessels leads to their occlusion and as a consequence to ischemic event,(24) but also this may be due to associated conditions such as dehydration, hypertension and not as a direct risk factor for stroke. The commonest etiologic factor for Hemorrhagic stroke was bleeding disorders. The high percentage could be attributed to including children of early age group, in which vit. $\mathrm{K}$ deficiency is common, and high number of children suffering from hematological disorders treated in ChildrenWelfare Teaching Hospital. Trauma was the second most common cause of Hemorrhagic stroke in our study, these findings did not match the results of Meyer-heim and Boltshauser,(25) Kumar et al (26) and Lin et al series,(27) in which Arteriovenous malformation represented the major cause of Hemorrhagic stroke, and bleeding disorders were much lower when compared to our study. This difference can be explained by the selection criteria of our patients that included both traumatic and spontaneous cases of Hemorrhagic stroke, however in their series spontaneous Intracerebral hemorrhage was only included. We found arteriovenous malformations and renal diseases accounted for $9.1 \%$ of Hemorrhagic stroke. Eleven patients had a multiple risk factors $(18 \%)$, where as no risk factors could also be identified in 11 patients $(18 \%)$. Lanthier et al (2) and others $(24,28)$ concluded in their studies that multiple risk factors are present in AIS and may be associated with a worse prognosis. As reported in various studies, despite extensive evaluation for an underlying etiology, some cases of stroke in childhood may remain cryptic.(24, 29, and 30) In our study some idiopathic stroke patients had systemic features like hepatomegaly which may suggest a metabolic disease as anetiologic factor. Three patients with ischemic stroke had metabolic disorders (two of them with mitochondrial disease and one with homocystinuria). Hemiplagia was a common presentation of ischemic stroke, followed by seizure, Bonuel et al (20) and ganesan et al (31) found that hemiparesis was the most prevalent symptom in the initial phase (83\%), followed by seizure (33\%). According to other literatures, seizures are a common presentation of stroke in childhood, and cortical damage is a major risk factor for seizures development. (24, 30, and 32) In Hemorrhagic stroke, disturbed level of consciousness was the most common (86.4\%), followed by seizure and hemiplegia. Ihab et al (33) found that impaired consciousness, vomiting, and headache were the main presenting symptoms. Other literatures (27.34) are quite homogeneous concerning the presenting symptoms in Hemorrhagic stroke in children.Regarding radiological findings, the results were agreed with other studies, which are also found a predominant involvement of the (Middle cerebral artery) MCA, $(29,35)$ as in our study the left MCA was more frequently affected than the right one, and as a consequence the right hemiplegia (or hemiparesis) was found as one of the most common motor deficits among children with ischemic stroke sequel. $(22,30,35)$ In our study, the most common site for Hemorrhagic stroke was lobar, which was consistent with Ihab et al. (33) Occipital lobe is a site for hemorrhage, which increase risk by 5.6 times.Hemorrhagic stroke was associated with an obvious reduction in risk of neurologic sequel by 2 times $(\mathrm{OR}=0.6)$ compared to ischemic type of stroke. Hemorrhagic stroke on the other hand obviously increases the risk of death as an outcome by 2.4 times compared to ischemic stroke. Both calculated estimates of risk (OR) failed to reach the level of statistical significance possibly because of small sample size. AL-Jarallah et al (34) found a mortality of $8.8 \%$, where as Lin et al (27) found a mortality of $6.1 \%$ in childhood stroke.

\section{Author contribution:}

DR.Husham z. Hammoodi: literature research, Data collection, interpretation, data analysis and drafting of manascipt.

DR. LamyaaAbdulkareem: Supervisor, study conception and design.

DR.Akram Al-Mahdawi: Supervisor and critical revision. 


\section{References:}

1. Fenichel G. Clinical pediatric neurology: A signs and symptoms approach. $6^{\text {th }}$ ed. Philadelphia: Saunders; 2009252

$p$.

2. Lanthier S, Carmant L, David M, Larbrisseau A, and deVeber G. Stroke in children: the coexistence of multiple risk factors predicts poor outcome. Neurology 2000 54:371-8.

3. Golomb MR, Fullerton HJ, Nowak-Gottl U, deVeber G. Male predominance in childhood ischemic stroke: findings from the International Pediatric Stroke Study. Stroke 2009 40:52-7.

4. Fullerton HJ, Wu YW, Zhao S, Johnston SC. Risk of stroke in children: ethnic and gender disparities. Neurology 2003 61: 189-94.

5. Kirton A, DeVeber G. Therapeutic approaches and advances in pediatric stroke: NeuroRx 2006 3:133-42.

6. KiKirkham F, Sebire G, Steinlin M, Strater R. Arterial ischaemic stroke in children. Review of the literature and strategies for future stroke studies. Thrombhaemost 2004 92: 697-706.

7. Pavlakis SG, Levinson K. Arterial ischemic stroke: common risk factors in newborns and children. Stroke 2009 40:S7981 .

8. Ganesan V, Prengler M, McShane MA, Wade AM, Kirkham FJ. Investigation of risk factors in children with arterial ischemic stroke. Ann Neurol 2003 53: 167-73.

9. Roach ES. Etiology of stroke in children. Semminpediatrneurol 2000 7: 244-60.

10. Amlie-Lefond C, Sébire G, Fullerton HJ. Recent developments in childhood arterial ischemic stroke. Lancet Neurol 2008 7: 425-35.

11. Daniel S. Tsze1, Jonathan H. Valente. Pediatric Stroke: A Revierw. Emergency Medicine International 2011734506 : 10 .

12. Moharir $M$, deveber $G$. pediatric arterial ischemic stroke. American academy of neurology 2014 20(2): 370-86.

13. Giroud M, Lemesle M, Madinier G, et al. Stroke in children under 16 years of age. Clinical and etiological difference with adults. Actaneurolscand 1997 Dec96(6): 401-6.

14. Visudhiphan P, Chiemchanya S, Wattanasirichaigoon D. strokes in thai children: etiology and outcome. Southeast asia J trop Med Public Health 1996 27: 801-5.

15. Al Sulaiman A, Bademosi O, Ismail H, Magboll G. stroke in Saudi children. J Child Neurol 1999 14: 295-8.

16. Salih MA, Abdel-Gader AG, Al-Jarallah AA, et al. Perinatal stroke in Saudi children. Clinical features and risk factors. Saudi Med J 200627 suppl 1: S35-40.

17. Salih MA, Abdel-Gader AG, Al-Jarallah AA, et al. Stroke in Saudi children. Epidemiology, clinical features and risk factors. Saudi Med J 2006 Mar 27 Suppl 1: S12-20.

18. Yock-Corrales A, Mackay MT, Mosley I, et al. Acute Childhood Arterial Ischemic and hemorrhagic Stroke in the Emergency Department. Ann Emerg Med 2011 Aug 58(2): 156-63.

19. Sträter $R$, Becker $S$, Eckardstein A, et al. Prospective assessment of risk factors for recurrent stroke during childhood-a 5 year follow up study. Lancet 2002360: 1540 45 .

20. Bonduel M, Sciuccati G, Hepner M, Torres AF, Pieroni G, Frontroth JP. Prethrombotic disorders in children with arterial ischemic stroke and sinovenous thrombosis. Arch Neural 1999 56: 967-71.

21. Ganesan V, McShane MA, Liesner R, Cookson J, Hann I, Kirkham FJ. Inherited prothrombotic states and ischaemic stroke in childhood. J Neural Neurosurg Psychiatry 1998 65: 508-11.

22. Günther $G$, Junker $R$, Sträter $R$, et al. Symptomatic ischemic stroke in full-term neonates. Role of acquired and genetic prothrombotic risk factors. Stroke 2000 31: 2437-41.

23. Mustafa A. Salih, Abdullah S. Al-Jarallah, et al. Cardiac diseases as a risk factor for stroke in Saudi children. Saudi Med J 2006 27: S61-68.

24. Kirkham FJ, Hogan AM. Risk factors for arterial ischemic stroke in childhood.CNSSpectr 2004 9:451-64.

25. Meyer-Heim AD, Boltshauser E. Spontaneous intracranial hemorrhage in children: etiology, presentation and outcome. Brain Dev 2003 25: 416-21.

26. Kumar R, Shukla D, Mahapatra AK. Spontaneous intracranial hemorrhage in children. PediatrNeurosurg 2009 45: 37-45.

27. Lin CL, Loh JK, Kwan AL, Howng SL. Spontaneous intracerebral hemorrhage in children. Kaohsiung J Med Sci 1999 15:146-51.

28. Barreirinho $S$, Ferro A, Santos $M$, et al. Inherited and acquired risk factors and their combined effects in pediatric stroke. PediatrNeurol 2003 28:134-38.

29. DeVeber G. Arterial ischemic strokes in infants and children: an overview of current approaches. SeminThrombHemost 2003 29:567-73.

30. Chung B, Wong V. Pediatric stroke among Hong Kong Chinese subjects. Pediatrics 2004 114:206-12.

31. Ganesan V, Hogan A, Shack N, Gordon A, Isaacs E, Kirkham FJ. Outcome after ischaemic stroke in childhood. Dev Med Child Neurol 2000 42:455-61.

32. Yang JS, Park YD, Hartlage PL. Seizures associated with stroke in childhood. PediatrNeurol 1995 12P 136-38.

33. Zidan I, Ghanem A. Intracerebral hemorrhage in children. Alexandria Journal of Medicine 2012 48: 139-45.

34. Al-Jarallah A, Al-Rifai MT, Riela AR, Roach ES. Nontraumatic brain hemorrhage in children: etiology and presentation. J child Neurol 2000 15: 284-9.

35. Rotta NT, Silva AR, Silva FLF, et al. Cerebrovascular disease in pediatric patients. ArqNeuropsiquiatr 200260: 95963. 